\title{
Quantification of Protodolomite Using a Combination of XRD, EDS, Z-contrast Imaging and Simulation
}

\author{
Yihang Fang and Huifang Xu \\ University of Wisconsin-Madison, Madison, Wisconsin, United States
}

Dolomite is a mineral with a stoichiometric chemical composition of $\mathrm{CaMg}\left(\mathrm{CO}_{3}\right)_{2}$ and an ordered arrangement of $\mathrm{Ca}$ and $\mathrm{Mg}$. Most natural dolomite have deviated from the stoichiometric composition and usually with more calcium and rarely with more magnesium. Cation ordering in dolomite refers to the alternating $\mathrm{Ca}$ and $\mathrm{Mg}$ layers along the c- axis results in the dolomite structure with $\mathrm{R}$ symmetry. $\mathrm{Ca}^{2+}$ and $\mathrm{Mg}^{2+}$ form octahedra with neighboring oxygens while carbon and three oxygen atoms form a trigonal planar motif. The dolomite $(\mathrm{R})$ structure violates the c-glide plane in the calcite structure (Rc), which results in an extra set of "b"-reflections" reflections with the presence of (10), (101), and (003) diffraction peaks in powder XRD pattern, in addition to the "a"-reflections" reflections that characterize Rc symmetry. The $d_{104}$ value of dolomite increases as Ca content increases or degree of ordering decreases $[1,2]$. Therefore, "b"-reflections" reflections and $d_{104}$ can be used to distinguish between the dolomite and calcite. Cation ordering in dolomite is commonly quantified using the intensity ratio of (10) and (110) reflections [3,4]. Parameters were proposed to describe the ordering states in dolomite such as $\mathrm{s}[5]$ and $\mathrm{s}^{*}[6]$. In this study, we used the $\mathrm{s}^{*}$ parameter to couple the ordering states with composition.

Dolomites, with 36-55\% $\mathrm{MgCO}_{3}$, formed in natural environments and synthesized under ambient conditions are either disordered, as evidenced by the absence of "b"-reflections" reflections in their powder XRD patterns, or weakly ordered with broad and diffused "b"-reflections" reflections. Higher temperature has resulted in faster dolomitization and higher ordering in dolomite [7]. Increasing cation ordering increases the thermodynamic stability of dolomite [3]. The high stability of ordered dolomite explains the observation that most ancient dolomites are well-ordered while the majority of modern dolomites are weakly ordered or disordered. Previous studies have recognized that the importance of understanding the factors controlling cation ordering is vital to deciphering the dolomite problem [7-9]. However, weak cation ordering results in decreasing "b"-reflection intensities and sometimes inability to quantify the ordering states of prodolomite using powder XRD. Therefore, we proposed a novel approach to quantify the ordering state of protodolomite by integrating Z-contrast imaging and image simulation. Through this combination method, the ordering states of protodolomite that may have been previously characterized as disordered on their low intensities of " $b$ "-reflections" reflections in powder XRD, can be determined. In this study, contour lines of the ordering states are constructed to provide a straightforward approach for quantifying weak ordering states of other protodolomite based on $d_{104}$ value and composition. This integrated approach provides a new tool and allows new insights and understanding on the weak ordering states in prodolomite and potentially other order-disorder systems such as omphacite in the diopside-jadeite series (Davidson and Burton, 1987). Also, from Z-contrast images, structural models of observed intergrowth and twin boundaries in $\mathrm{Ca}-\mathrm{Mg}$ carbonate can be constructed that explains the transition from disordered dolomite to protodolomite and eventually to ordered dolomite.

However, the strongest ' $b$ ' '-reflection (10) has only 5.4\% intensity of (104) for ordered dolomite [10], and its intensity decrease does not behave linearly with decreasing cation ordering. Therefore, it is impossible to identify and quantify the weak ordering state of protodolomite $\left(\mathrm{s}^{*}=0.5\right)$ using powder XRD especially in natural samples with the presence of other phases. Some Holocene dolomite is more ordered, and the ordering states can be quantified using traditional powder XRD [11]. Intensity of spots in the 
electron diffraction pattern from TEM is also unable to quantify the ordering state due to unreliable intensity from multiple diffractions. To quantify weak ordering states in Ca-Mg carbonates, we constructed a new approach by combining Z-contrast imaging and image simulation based on the known composition of protodolomite crystals.
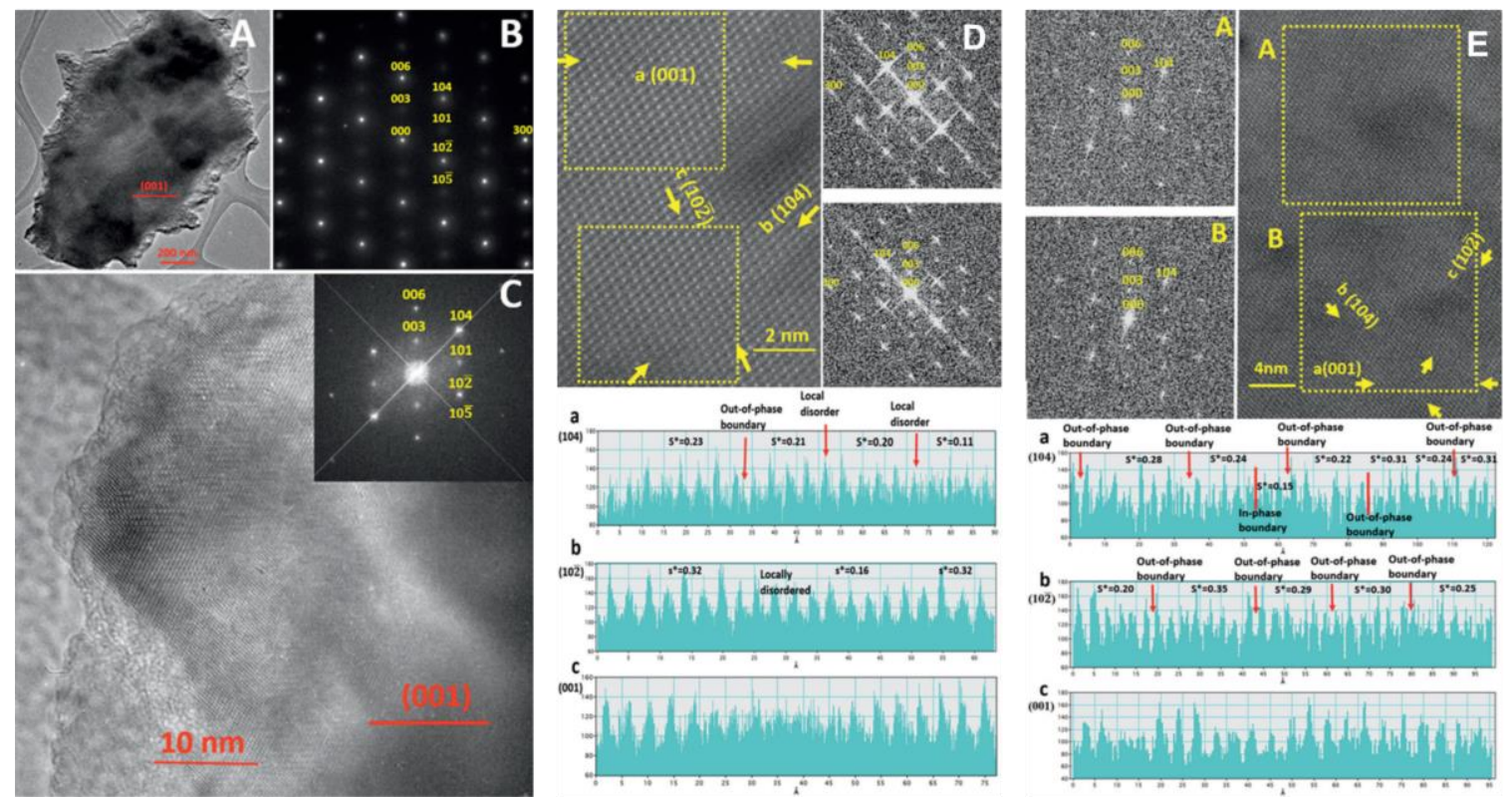

Figure 1. Bright-field TEM image (A-C) showing a partially ordered dolomite with diffuse "b"-reflection. STEM images, intensity profiles along (104), (102), (001) direction, and local ordering states for a 46 mol\% (D) and $\sim 52 \mathrm{~mol} \%$ (E) $\mathrm{MgCO} 3$ protodolomite.
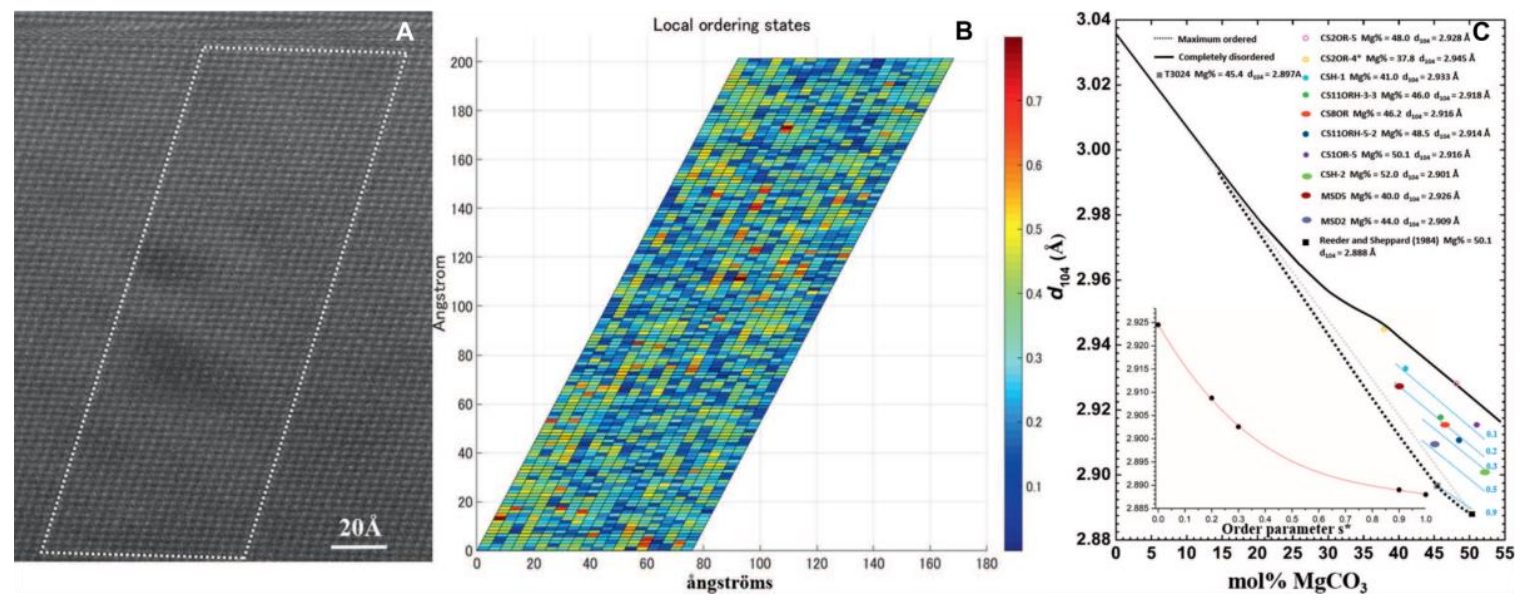

Figure 2. Z-contrast image (A) and the intensity-based calculated ordering states map (B). C) d104 vs mol\% $\mathrm{MgCO} 3$ with ordering contour lines for protodolomite.

\section{References}

Antao, S.M.; Mulder, W.H.; Hassan, I.; Crichton, W.A.; Parise, J.B. Cation disorder in dolomite, $\mathrm{CaMg}(\mathrm{CO} 3) 2$, and its influence on the aragonite + magnesite $\leftrightarrow$ dolomite reaction boundary. Am. Mineral. 2004, 89, 1142-1147.

Zhang, F.; Xu, H.; Konishi, H.; Roden, E.E. A relationship between d104 value and composition in the calcite-disordered dolomite solid-solution series. Am. Mineral. 2010, 95, 1650-1656. 
Graf, D.L.; Goldsmith, J.R. Some Hydrothermal Syntheses of Dolomite and Protodolomite. J. Geol. 1956, 64, 173-186.

Gregg, J.M.; Bish, D.L.; Kaczmarek, S.E.; Machel, H.G. Mineralogy, nucleation and growth of dolomite in the laboratory and sedimentary environment: A review. Sedimentology 2015, 62, 1749-1769.

Reeder, R.J.; Wenk, H.R. Structure refinements of some thermally disordered dolomites. Am. Mineral. 1983, 68, 769-776.

Fang, Y.; Xu, H. A new approach to quantify ordering state of protodolomite using XRD, TEM, and Zcontrast imaging. J. Sediment. Res. 2019, 89, 537-551.

Kaczmarek, S.E.; Thornton, B.P. The effect of temperature on stoichiometry, cation ordering, and reaction rate in high-temperature dolomitization experiments. Chem. Geol. 2017, 468, 32-41.

Gregg, J.M.; Bish, D.L.; Kaczmarek, S.E.; Machel, H.G. Mineralogy, nucleation and growth of dolomite in the laboratory and sedimentary environment: A review. Sedimentology 2015, 62, 1749-1769.

Kaczmarek, S.E.; Gregg J.M.; Bish, D.; Machel, H.; Fouke, B. Dolomite, very high-magnesium calcite, and microbes - implications for the microbial model of dolomitization, in Characeterization and Modeling of Carbonates - Mountjoy Symposium 1. In SEPM Special Publication; MacNeil, A., Lonnee, J., Wood, R., Eds.; 2017; Vol. 109, p. 17.

Graf, D.L. Crystallographic tables for the rhombohedral carbonates. Am. Mineral. 1961, 46, 1283-1316. Gregg, J.M.; Howard, S.A.; Mazzullo, S.J. Early diagenetic recrystallization of Holocene (< 3000 years old) peritidal dolomites, Ambergris Cay, Belize. Sedimentology 1992, 39, 143-160. 